\title{
Identification of highly conserved and species-specific polypeptides of Haemophilus ducreyi
}

\author{
MICHELLE J. ALFA*, CHUN-LIN YANG* , L. A. SLANEY, ANITA Y. C. KWOK*, A. R. RONALD* $\dagger$ \\ and F. T. JAY* $\ddagger$
}

Departments of * Medical Microbiology and $\uparrow$ Medicine, Faculty of Medicine, University of Manitoba, Winnipeg, Manitoba, Canada R3E OW3

\begin{abstract}
Summary. Chancroid is a sexually transmitted diseased caused by Haemophilus ducreyi. The pathological manifestations of chancroid are unique among Haemophilus species and the virulence factors of $H$. ducreyi that account for these features have not been identified. Some of these virulence factors may be unique components of $H$. ducreyi, but attempts to identify H. ducreyi-specific components have been unsuccessful. Four polypeptides-A, B, C and D of $83,77,56$ and $28 \mathrm{kDa}$, respectively - were identified with a panel of nine $H$. ducreyi-specific monoclonal antibodies (MAbs). Polypeptide $\mathrm{C}$ was one of the five major proteins in $H$. ducreyi and demonstrated micro-heterogeneity in SDS-PAGE. Polypeptides A, B and D were present in only small amounts in whole-cell lysates of $H$. ducreyi. The relative amounts of A and $B$ varied, suggesting that they may be precursor molecules. The unique polypeptides $C$ and $D$ were not exposed on the surface. Polypeptide $C$ was highly soluble and did not appear to be membrane-bound, whereas polypeptide $\mathrm{D}$ appeared to partition with the cytoplasmic membrane and was soluble in Sarkosyl. All four polypeptides appeared to be unique to $H$. ducreyi since MAbs directed against them did not cross-react with $H$. influenzae, $H$. parainfluenzae or Neisseria gonorrhoeae. The mol. wts of all of these polypeptides were conserved throughout 35 clinical isolates collected from 15 cities in eight countries and one reference strain of $H$. ducreyi that were tested. Based on the immune cross-reactivities, it was concluded that the four polypeptides belonged to a family of proteins with partial sequence homology that may have been derived from the same precursor polypeptide or the same transcription unit. A sequence relationship model for the polypeptides was proposed based on their cross-reactivities with the MAbs.
\end{abstract}

\section{Introduction}

Haemophilus ducreyi is the aetiological agent of chancroid, a sexually transmitted disease that is characterised by genital ulcers and painful, swollen, regional lymph nodes that may suppurate to form "buboes". Although $H$. ducreyi does not spread systemically, the virulence factors that allow it to evade the host defence mechanisms and localise in the regional lymph nodes are as yet unknown. However, the pathological manifestations of infection with $H$. ducreyi are very different from those of diseases caused by other Haemophilus species. ${ }^{1,2}$ It is expected that at least some of the virulence factors of $H$. ducreyi must be unique to this micro-organism. Attempts to identify those unique components have not been extensive and have been largely unsuccessful because of the extensive immune cross-reactivity of $H$. ducreyi with other Haemophilus spp. Injection of $H$. ducreyi into rabbits results in a strong humoral response, but the antisera also cross-react strongly with $H$. influenzae and $H$. parainfluenzae. ${ }^{3-5}$ This high degree of crossreactivity has contributed to the difficulty of identifying those components that are unique to $H$. ducreyi. Odumeru et al. ${ }^{6}$ demonstrated that $c .50 \%$ of the anti$H$. ducreyi antibodies produced in rabbits or mice cross-reacted with antigens of $H$. influenzae or $H$. parainfluenzae. Indeed, Hansen and Loftus ${ }^{7}$ and Schalla et al. ${ }^{8}$ have attempted to develop monoclonal antibodies (MAbs) specific to $H$. ducreyi. The antigens recognised by these MAbs have not been fully characterised. Because of these problems, no $H$. ducreyispecific polypeptides have been identified and little is known about $H$. ducreyi-specific components.

Based on a competition-adsorption method for hybridoma screening, a panel of nine independently isolated hybridoma clones producing $H$. ducreyispecific MAbs was produced. ${ }^{6}$ This report describes the identification and characterisation of four polypeptides that are recognised by the $H$. ducreyi-specific 
MAbs and their localisation and conservation among clinical isolates.

\section{Materials and methods}

\section{Bacterial stock cultures}

The strains of $H$. ducreyi used in this study were clinical isolates and represented strains collected from around the world (table). They were maintained in skimmed milk at $-70^{\circ} \mathrm{C}$ until required. The $H$. ducreyi strains were propagated on chocolate blood agar supplemented with Isovitalex (BBL) $1 \%$ and horse serum $5 \% \mathrm{v} / \mathrm{v}$ at $34^{\circ} \mathrm{C}$ in high humidity and $\mathrm{CO}_{2} 5 \%$ in air.

\section{Monoclonal antibodies}

The production and initial characterisation of the panel of nine $H$. ducreyi MAbs was described by Odumeru et $a l^{6}$ In this study, ascites fluid was produced by injecting $1 \times 10^{6}$ hybridoma cells intraperitoneally into $\mathrm{BALB} / \mathrm{c}$ mice (University of

Table. $H$. ducreyi strains*

\begin{tabular}{|c|c|c|}
\hline $\begin{array}{c}\text { Sample } \\
\text { no. }\end{array}$ & $\begin{array}{c}\text { Strain } \\
\text { designation }\end{array}$ & Source \\
\hline 1 & 35000 & Winnipeg, MB, Canada \\
\hline 2 & 35199 & Winnipeg, MB, Canada \\
\hline 3 & 54198 & Winnipeg, MB, Canada \\
\hline 4 & 78226 & Winnipeg, MB, Canada \\
\hline 5 & CIP542 & Paris, France \\
\hline 6 & GV072 & Bathurst, Gambia \\
\hline 7 & GV073 & Bathurst, Gambia \\
\hline 8 & 181 & Nairobi, Kenya \\
\hline 9 & $409 \dagger$ & Nairobi, Kenya \\
\hline 10 & 9468 & Nairobi, Kenya \\
\hline 11 & AX557 & Nairobi, Kenya \\
\hline 12 & BG407 & Nairobi, Kenya \\
\hline 13 & BG411 & Nairobi, Kenya \\
\hline 14 & C13 & Nairobi, Kenya \\
\hline 15 & C143 & Nairobi, Kenya \\
\hline 16 & HD013 & Amsterdam, Netherlands \\
\hline 17 & HD014 & Amsterdam, Netherlands \\
\hline 18 & E1673 & Stockholm, Sweden \\
\hline 19 & HD1 & Stockholm, Sweden \\
\hline 20 & $\mathrm{CH} 2$ & Bangkok, Thailand \\
\hline 21 & CH39 & Bangkok, Thailand \\
\hline 22 & PU1 & Bangkok, Thailand \\
\hline 23 & $\mathrm{CA} 173$ & California, USA \\
\hline 24 & WPB506 & W. Palm Beach, CA, USA \\
\hline 25 & WPB511 & W. Palm Beach, CA, USA \\
\hline 26 & $6 \mathrm{~V}$ & Atlanta, GA, USA \\
\hline 27 & 108 & Atlanta, GA, USA \\
\hline 28 & OR574 & Orlando, FL, USA \\
\hline 29 & MASS576 & Boston, MA, USA \\
\hline 30 & MASS579 & Boston, MA, USA \\
\hline 31 & NY006 & New York, NY, USA \\
\hline 32 & NY012 & New York, NY, USA \\
\hline 33 & OH 1075 & Ohio, USA \\
\hline 34 & VII58 & Seattle, WA, USA \\
\hline 35 & VII59 & Seattle, WA, USA \\
\hline 36 & $36-\mathrm{F}-2$ & Reference strain \\
\hline
\end{tabular}

*These bacterial strains were derived from A. R. Ronald's collection of $H$. ducrey $i$ isolates that were originally isolated in the countries indicated.

†Strain 409 was used for the immunisation of mice in the production of the MAbs ${ }^{6}$ and was used in the present study.
Manitoba Central Animal Unit) that had been primed 7 days earlier with an intraperitoneal injection of $0.5 \mathrm{ml}$ of pristane. Cells and debris were removed by centrifugation at $6000 \mathrm{~g}$ for $10 \mathrm{~min}$ and the ascites fluid was then stored at $-20^{\circ} \mathrm{C}$ until required.

\section{SDS-PAGE and Western immunoblotting procedures}

$H$. ducreyi 409 cells from 48-h cultures were solubilised in sample buffer $(62.5 \mathrm{~mm}$ Tris- $\mathrm{HCl}$, $\mathrm{pH} 6.5 ; \operatorname{SDS} 2 \% \mathrm{w} / \mathrm{v}, 2$-mercaptoethanol $5 \% \mathrm{v} / \mathrm{v}$, glycerol $10 \% \mathrm{v} / \mathrm{v}$, bromophenol blue $0.01 \% \mathrm{w} / \mathrm{v}$ ) and heated at $98^{\circ} \mathrm{C}$ for $5 \mathrm{~min}$. The protein bands were separated by electrophoresis on a discontinuous gel ${ }^{9}$ consisting of acrylamide $12.5 \%$ and bis-acrylamide $0.5 \%$. The gel was either stained with Coomassie Blue or transferred electrophoretically to nitrocellulose $(0.22 \mu \mathrm{m}$ pore diameter, Schleicher and Schull) at $200 \mathrm{~mA}$ for $4 \mathrm{~h}$. The immunoblotting buffer consisted of $25 \mathrm{~mm}$ Tris base (BioRad Laboratories), $200 \mathrm{~mm}$ glycine (BioRad Laboratories) and methanol $20 \% \mathrm{v} / \mathrm{v}$. Residual protein binding sites were blocked by incubating the nitrocellulose in bovine serum albumin (BSA; Sigma) $3 \% \mathrm{w} / \mathrm{v}$ in Tris-buffered saline (TBS; $20 \mathrm{~mm}$ Tris- $\mathrm{HCl}, 500 \mathrm{~mm} \mathrm{NaCl}, \mathrm{pH} \mathrm{7.5)}$ ) at room temperature for $4 \mathrm{~h}$. The nitrocellulose was then incubated with the appropriate MAb diluted 1 in 100 in BSA-TTBS (BSA $1 \% \mathrm{w} / \mathrm{v}$, Tween $200.05 \% \mathrm{v} / \mathrm{v}$ in TBS) at $4^{\circ} \mathrm{C}$ for $18 \mathrm{~h}$. After washing the nitrocellulose three times for $30 \mathrm{~min}$ each with TTBS to remove unbound MAb, the nitrocellulose was incubated for $2 \mathrm{~h}$ at room temperature with peroxidase-conjugated goat anti-mouse IgG, IgM, IgA (Cedar Lane) diluted 1 in 1000 in BSA-TTBS. The nitrocellulose was then washed three times for $30 \mathrm{~min}$ with TTBS to remove unbound peroxidase conjugate. Colour was developed with 4-4 chloro-napthol (BioRad) as described by the manufacturer.

\section{${ }^{125}$ I-Iodination of cell-surface components}

The method of Fraker and Speck ${ }^{10}$ was used to iodinate the outer-membrane proteins (OMPs) of $H$. ducreyi. Briefly, a whole-cell suspension of a 24-h culture of $H$. ducreyi was washed once with PBS. Clumps were allowed to settle and the homogeneous portion of the cell suspension $(50 \mu \mathrm{l})$ was pipetted into a glass vial that had been coated previously with $1 \mu \mathrm{g}$ of Iodagen (Pierce Chemical Co.). Carrier-free ${ }^{125} \mathrm{I}(0.5 \mu \mathrm{Ci})$ was added and the reaction was allowed to proceed for $15 \mathrm{~min}$. The $H$. ducreyi suspension was removed from the reaction tube and washed three times with $200 \mu$ l of PBS to remove unbound ${ }^{125}$ I. The trichloroacetic acid precipitability of such labelled preparations was $>95 \%$. The ${ }^{125}$ I-labelled $H$. ducreyi cells were solubilised in sample buffer, heated at $98^{\circ} \mathrm{C}$ for $5 \mathrm{~min}$ and then stored at $-20^{\circ} \mathrm{C}$ until required.

\section{Subcellular fractionation}

$H$. ducreyi cells were suspended in TBS and disrupted at $-20^{\circ} \mathrm{C}$ in an X-press (Fred S. Carver Inc., 
NJ, USA). The cell debris was collected by centrifugation at $10000 \mathrm{~g}$ for $20 \mathrm{~min}(\mathrm{P}-10)$. The supernate (S-10) was further fractionated by centrifugation at $100000 \mathrm{~g}$ for $60 \mathrm{~min}$. The high speed supernate (S-100) was collected. The pellet (P-100) was extracted with sodium lauryl sarcosinate (Sarkosyl) $2 \%(\mathrm{w} / \mathrm{v})$ in $10 \mathrm{~mm}$ HEPES, pH 7.4, and separated by centrifugation at $100000 \mathrm{~g}$ for $60 \mathrm{~min}$ into the Sarkosyl extract supernate (SS-100) and the pellet containing the detergent-insoluble outer-membrane fraction $\left(\mathrm{OMP}^{11,12}\right)$. The final volume at each stage was adjusted to maintain equivalent relative volume $(1 \mathrm{ml})$. A sample of each cell fraction was saved for quantitative comparison by SDS-PAGE.

\section{Results}

The proteins from $H$. ducreyi cells lysed in SDS, separated by SDS-PAGE and blotted on to nitrocellulose were probed with the nine MAbs that reacted specifically with $H$. ducreyi and did not cross-react with other Haemophilus species ${ }^{6}$ (fig. 1). Four $H$. ducreyi polypeptides, $\mathrm{A}, \mathrm{B}, \mathrm{C}$ and $\mathrm{D}$, of $83,77,56$ and $28 \mathrm{kDa}$, respectively, were recognised by the nine MAbs in the panel (fig. 1). MAbs MHd083 and

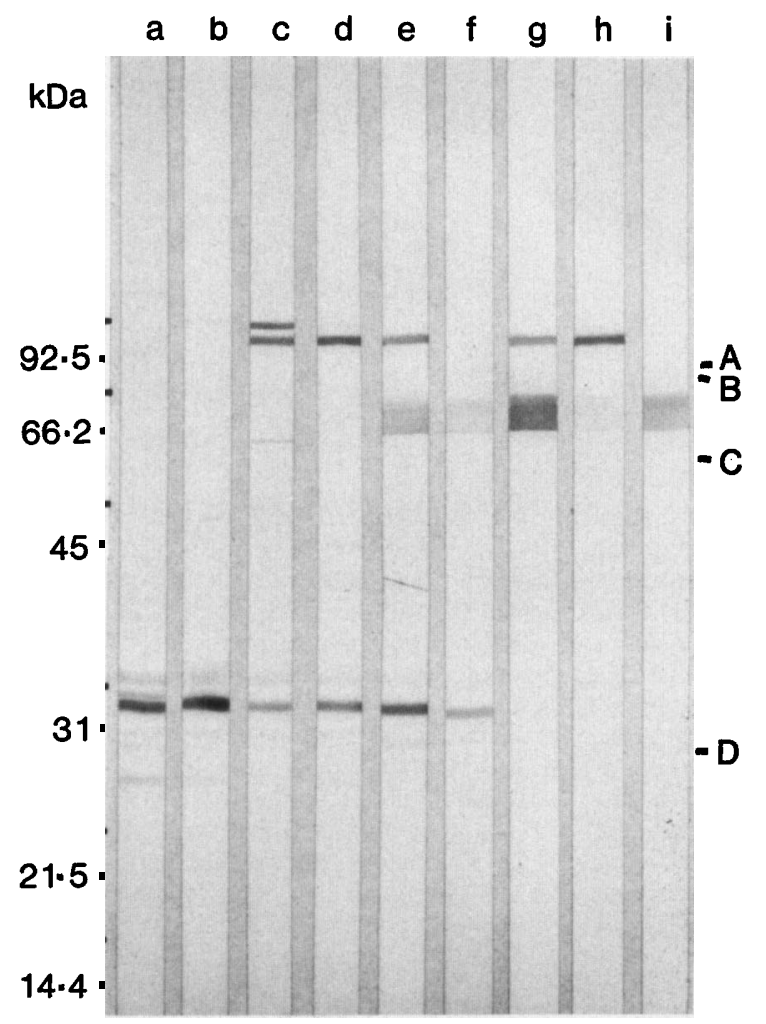

Fig. 1. Identification of $H$. ducreyi polypeptides recognised by the $H$. ducreyi-specific MAbs. Whole-cell preparations of $H$. ducreyi 409 ( $7 \mu \mathrm{g} /$ lane) were solubilised in sample buffer, resolved by SDSPAGE and electroblotted on to nitrocellulose. The nitrocellulose strips were separately probed with MAbs MHd083 (lane a), MHd084 (b), MHd078 (c), MHd080 (d), MHd072 (e), MHd107 (f), MHd091 (g), MHd082 (h) and MHd086 (i). The migration of biotinylated mol.-wt markers $(\mathrm{kDa})$ phosphorylase $\mathrm{B}(92 \cdot 5)$, bovine serum albumin (66.2), ovalbumin (45), carbonic anhydrase (31), soybean trypsin inhibitor $(21.5)$ and lysozyme $(14.4)$ are indicated.
MHd084 were specific for polypeptide D (fig. 1, lanes $a$ and $b$ ), and MAb MHd086 reacted only with polypeptide $\mathrm{C}$ (fig. 1, lane i). However, each of the other MAbs reacted with multiple polypeptides. MAb MHd078 reacted with polypeptides A, B and D (fig. 1, lane c) and MAb MHd072 recognised polypeptides B, C and D (fig. 1, lane e). Both MAbs MHd082 and MHd091 bound to polypeptides B and C (fig. 1, lanes $\mathrm{g}$ and $\mathrm{h}$ ), although the reactivity of MAb MHd082 with polypeptide $C$ (fig. 1, lane $h$ ) was very weak. The similar reactivity of MAbs MHd082 and MHd091 suggests binding to a similar region but the relative reactivity of binding indicates that they may bind different epitopes. MAb MHd107 (fig. 1, lane f) appeared to have specificity similar to that of $\mathrm{MAb}$ MHd072 (fig. 1, lane e) but its reactivity with polypeptides $B$ and $C$ was very weak. Although polypeptide A was detected in all strains tested, the relative concentration of polypeptide A varied from one preparation to another, suggesting that it may be an unstable pre-protein. The immune cross-reactivity indicated an antigenic relationship between polypeptides A, B, C and D (fig. 1).

The presence of these $H$. ducreyi-specific polypeptides was tested by Western immunoblotting against 35 isolates of $H$. ducreyi collected from eight countries around the world and one reference strain, 36-F-2. Because of the variability in the relative concentration of polypeptide A, only polypeptides B, $C$ and $D$ were studied further. MAb MHd072 was used to assess the presence of polypeptides $B$ and $D$ and MAb MHd091 was used to assess the presence of polypeptide C. As shown in fig. 2, not only was an antigenic analogue of each of polypeptides B, C and D detected in all the isolates tested but also the apparent mol. wts of the polypeptides were conserved, as determined by immunoblot after SDS-PAGE, in all of the $36 \mathrm{H}$. ducreyi strains tested. Therefore, these antigens were not only unique to $H$. ducreyi but also appeared to be ubiquitous within the species with extremely well conserved mol. wts among all the $H$. ducreyi strains. No other $H$. ducreyi-specific polypeptide that was not related to this family of polypeptides was recognised by the panel of MAbs studied.

To determine whether any of these polypeptides was exposed on the cell surface, $H$. ducreyi whole cells were surface ${ }^{125}$ I-iodinated, washed and solubilised in SDS. The proteins were separated by SDS-PAGE and then the ${ }^{125}$ I-labelled bands were detected by autoradiography (fig. 3A, lane 9 ). The $31-\mathrm{kDa}$ polypeptide was predominantly radiolabelled followed by the 40 -, 44- and 47-kDa protein bands. None of these radiolabelled bands corresponded to the $H$. ducreyi-specific polypeptide C detected with MAb MHd086 in an immunoblot (fig. 3B, lane 8), or polypeptides B and D based on their apparent mol. wts (fig. 1).

To determine whether any of these polypeptides could be a component of the outer membrane (OM) which cannot be labelled by our surface iodination method, the OM was isolated by the Sarkosyl ex- 


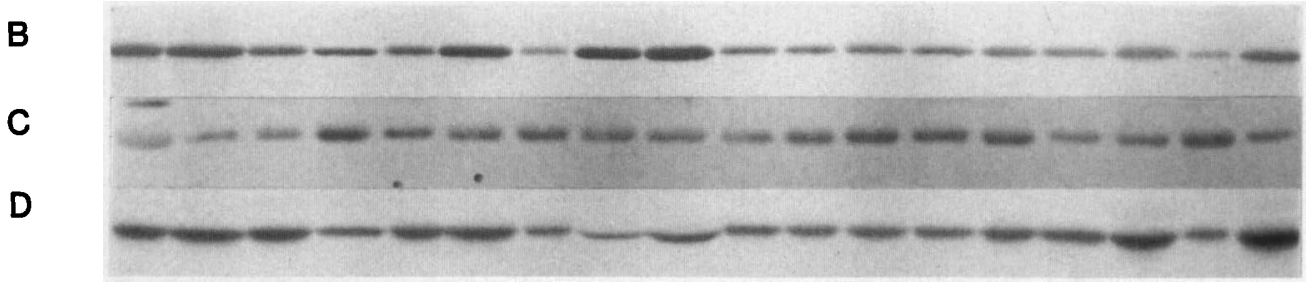

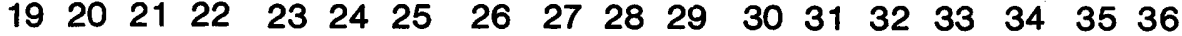

B

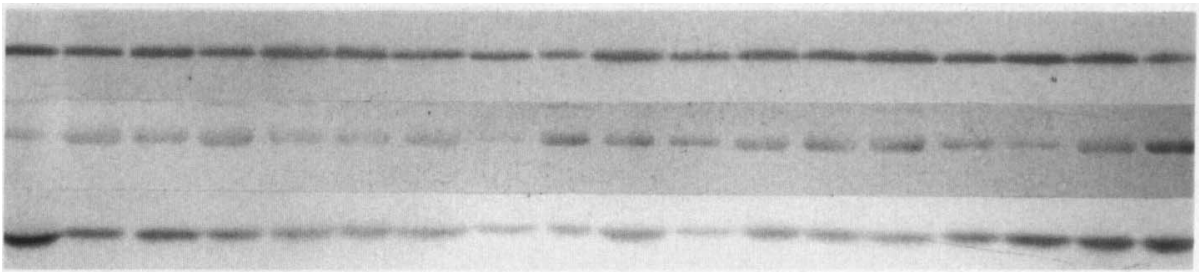

Fig. 2. Detection of epitopes bound by $H$. ducreyi-specific MAbs in different $H$. ducreyi isolates. Cells of individual $H$. ducreyi isolates were lysed in sample buffer at $95^{\circ} \mathrm{C}$, separated by SDS-PAGE and blotted on to nitrocellulose. For immunoblot detection of polypeptide $\mathrm{C}(\mathrm{C})$ with MHd091, $1 \mu \mathrm{g}$ of cell protein/lane was analysed; for the detection of polypeptides B (B) and D (D) with MHd072, 10 $\mu \mathrm{g} / \mathrm{lane}$ was loaded on the gel. The lane designations for individual bacterial strains tested are provided in the table. Only the relevant areas of the immunoblots showing the polypeptides are shown in the composite figure.

A $\quad 1 \quad 2 \quad 3 \quad 4 \quad 5 \quad 6 \quad 7 \quad 8 \quad 9$

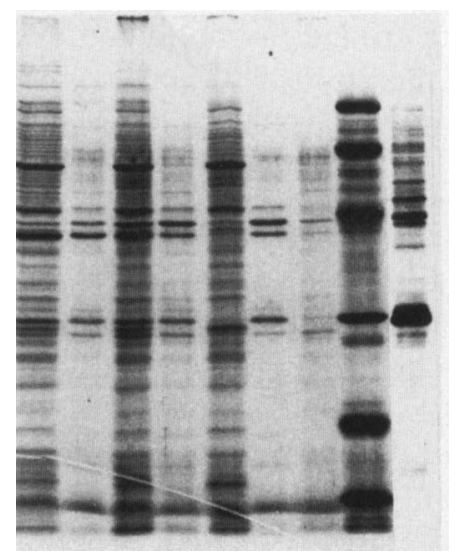

C

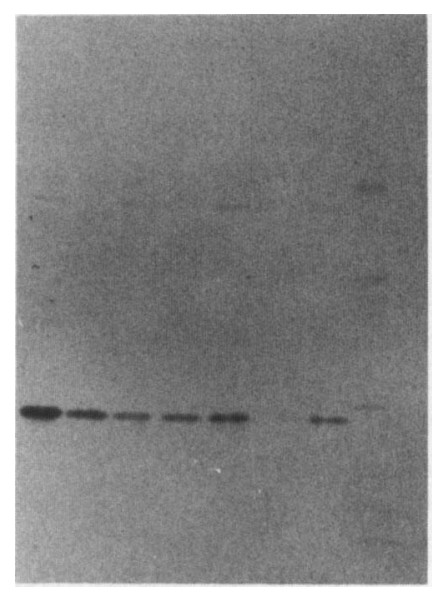

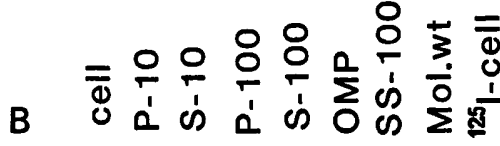

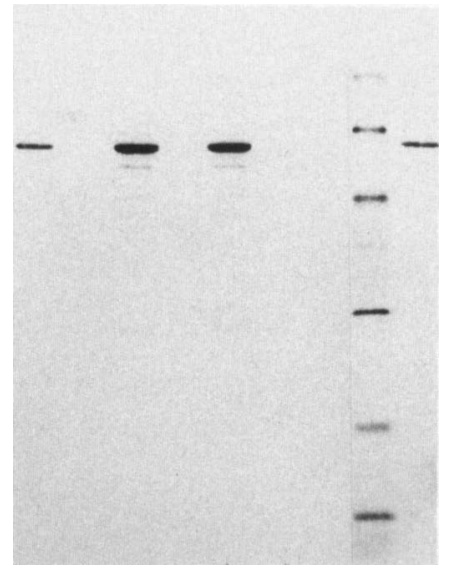

Fig. 3. Subcellular localisation of $H$. ducreyi-specific polypeptides. Whole cells of $H$. ducreyi 409 (lane 1) were lysed by X-press and clarified by centrifugation at $10000 \mathrm{~g}$ to remove cell debris (P-10; lane 2). The supernate (S-10; lane 3) was further fractionated by centrifugation at $100000 \mathrm{~g}$ into the high speed pellet (P-100; lane 4) and high speed supernate (S-100; lane 5), respectively. The pellet was resuspended and extracted with Sarkosyl $2 \%$ and centrifuged at $100000 \mathrm{~g}$ for $60 \mathrm{~min}$ to separate the detergent-insoluble outermembrane preparation (OMP; lane 6) from the Sarkosyl extract (SS-100; lane 7). The final relative volume of each fraction $(1 \mathrm{ml})$ was maintained constant for final analyses $(10 \mu \mathrm{l} /$ lane) by SDSPAGE, visualised by Coomassie Brilliant Blue (Panel A), and immunoblots, with MAb MHd086 to detect polypeptide C (panel B) and MAb MHd084 to detect polypeptide D (panel C). The presence of polypeptide B in the OMP fraction was tested for with MAb MHd082 (panel C, lane 9). Whole cells that had been surface ${ }^{125} \mathrm{I}$ labelled were analysed by SDS-PAGE and the labelled polypeptide bands were visualised by autoradiography (panel $A$, lane 9) and immunoblotted for polypeptide $\mathbf{C}(\mathbf{B}$, lane 9). The Coomassie Bluestained mol.-wt markers (lane A8) and biotinylated mol.-wt markers (lane B8, C8) were similar to those described in fig. 1 .

detected by autoradiography (fig. 3A, lane 9). However, none of the protein bands in the OMP fraction co-migrated with polypeptides B, C and D (fig. 1) and traction method and separated by SDS-PAGE (fig. $3 A$, lane 6). The OMP profile (fig. 3A, lane 6) was similar to the surface-iodinated cell-protein profile 
polypeptide C (fig. 3B, lane 6), B or D (fig. 3C, lane 6, 9) were not detected in the Sarkosyl-insoluble OMP fraction by immunoblotting with MAbs MHd086, 082 and 084 , respectively. Polypeptides B, C and D must not be part of the OMP structure. Although all these polypeptides were found in the soluble fraction, the subcellular distribution of polypeptide $D$ was slightly different from that of polypeptides B and C. As shown in fig. 3B, polypeptide $C$ segregated into the $S-10$ and S-100 fractions (fig. 3B, lanes 3, 5) but not in the P-10 or P-100 fractions (fig. 3B, lanes 2 and 4), indicating that it is a soluble protein which is likely to be located in the cytosol or the periplasmic space. However, the detection of polypeptide D in the P-10 and P-100 fractions (fig. 3C, lanes 2 and 4), in addition to its presence in the S-10, S-100 and SS-100 (fig. 3C, lanes 3, 5 and 7), but not in the Sarkosyl-insoluble OMP fraction (fig. 3C, lane 6) indicated that a fraction of polypeptide D may be associated with the cytoplasmic membrane.

\section{Discussion}

The nine independently isolated MAbs specific for $H$. ducreyi $i^{6}$ recognised only four separate polypeptides designated A, B, C and D (fig. 1) of $83,77,56$ and $28 \mathrm{kDa}$, respectively. The epitopes bound by the MAbs on these four polypeptides were unique to $H$. ducreyi since the MAbs did not cross-react with whole cells or cell lysates of different strains of $H$. influenzae, $H$. parainfluenzae or $N$. gonorrhoeae, ${ }^{6}$ or Treponema pallidum (Nichols strain), Escherichia coli 392 or Staphylococcus aureus (Cowan strain). The antigens recognised by these $H$. ducreyi-specific MAbs appeared to be distinct from that recognised by the MAb 10-14-kDa produced by Hansen and Loftus. ${ }^{7}$ The 46-, 41- and 28-kDa polypeptides described by Abeck et al. ${ }^{11}$ that reacted with immune mouse sera correlate with the surface-labelled OMPs reported here (fig. 3A, lane 9) as well those described by Abeck and Johnson. ${ }^{12}$

Polypeptide $\mathrm{C}$ was one of the most abundant proteins in the whole-cell profile of $H$. ducreyi whereas polypeptide $\mathrm{D}$ was a minor component and polypeptides A and B could barely be detected by Coomassie Blue staining (fig. 3A, lane 1). The immune cross-reactivities of the MAbs with the four polypeptides indicated that the latter must belong to a family of polypeptides with varying extent of sequence homologies. Furthermore, polypeptide $\mathrm{A}$, which has the largest mol. wt and exhibits variable concentration in the cell, may be a pre-protein for some of the small and more stable members of the family.

Unlike OMP profiles, that can vary significantly between different strains, ${ }^{13.14}$ polypeptides $\mathrm{B}, \mathrm{C}$ and $\mathrm{D}$ were conserved in all 36 isolates of $H$. ducreyi collected from 15 cities in eight countries over a span of more than 40 years (36-F-2, Pittman strain, 1943). Not only were antigenic analogues of each of these polypeptides detected in Western blots with MAbs, but also the mol. wts of each of these polypeptides were completely conserved among all clinical isolates tested. The extent of conservation in the amino-acid sequences and nucleotide sequences must await the purification or molecular cloning of these polypeptides. However, based on the obligatory expression and conservation of the mol. wts of these $H$. ducreyi-unique polypeptides, it is likely that these polypeptides may have an important role in the biology of the organism or the pathogenesis of chancroid, or both, in order to be selected against random mutation as seen in many cellular proteins, including the OMPs. ${ }^{11,15}$

To determine whether these bacterial components are presented on the cell surface for interaction with the host, $H$. ducreyi whole cells were surface-labelled with ${ }^{125} \mathrm{I}$ by the Iodagen method. Iodagen is waterinsoluble and, once coated on to the glass surface of the reaction tube, very little can become detached in aqueous solution to penetrate the cell during iodination. $^{10}$ As a result, predominantly surface-exposed components are labelled. SDS-PAGE analysis of surface-iodinated $H$. ducreyi strain 409 indicated that there were four surface-exposed polypeptides of 46 , 44,41 and $31 \mathrm{kDa}$, respectively (fig. $3 \mathrm{~A}$, lane 9). The $31-\mathrm{kDa}$ component was the most heavily radiolabelled. This is consistent with the observation of Abeck and Johnson ${ }^{12}$ that the 27-30.5-kDa bands of the OMPs isolated after Sarkosyl extraction from $H$. ducreyi strains $4,6,8,47,35000$ and $\mathrm{M}$, were most heavily radiolabelled by the Iodagen method. None of the radiolabelled surface-exposed polypeptides corresponded to any of the $H$.ducreyi-specific polypeptides identified by our MAbs. Since the labelling procedure would identify only those surface components that have accessible tyrosine and tryptophan residues for solid-phase iodination, outer-membrane preparations were also prepared by the Sarkosyl extraction method $^{13,14}$ and separated on SDS-PAGE to identify all OMPs, including those that may not be surface exposed. The SDS-PAGE profile of the Sarkosylinsoluble material demonstrated four major protein bands (fig. 3A, lane 6), which corresponded to four of the major bands identified by surface labelling (fig. 3A, lane 9). None of these four major OMPs had apparent mol. wts corresponding to those recognised by the $H$. ducreyi-specific MAbs (fig. 1). Therefore, based on the working definition of solid-phase iodination as the criterion for cell-surface exposure and Sarkosyl insolubility of the outer membrane, polypeptides B, C and D must not be presented on the cell surface or form part of the outer-membrane structure of H. ducreyi. It is interesting to note that while all three polypeptides exist in the soluble fraction of the cell, either in the cytosol or the periplasmic space, or both, a fraction of polypeptide $\mathrm{D}$ may be associated with the plasma membrane.

The fact that polypeptides A, B and D cross-reacted with MAb MHd078, suggested that they must carry the same epitope and are therefore likely to have 


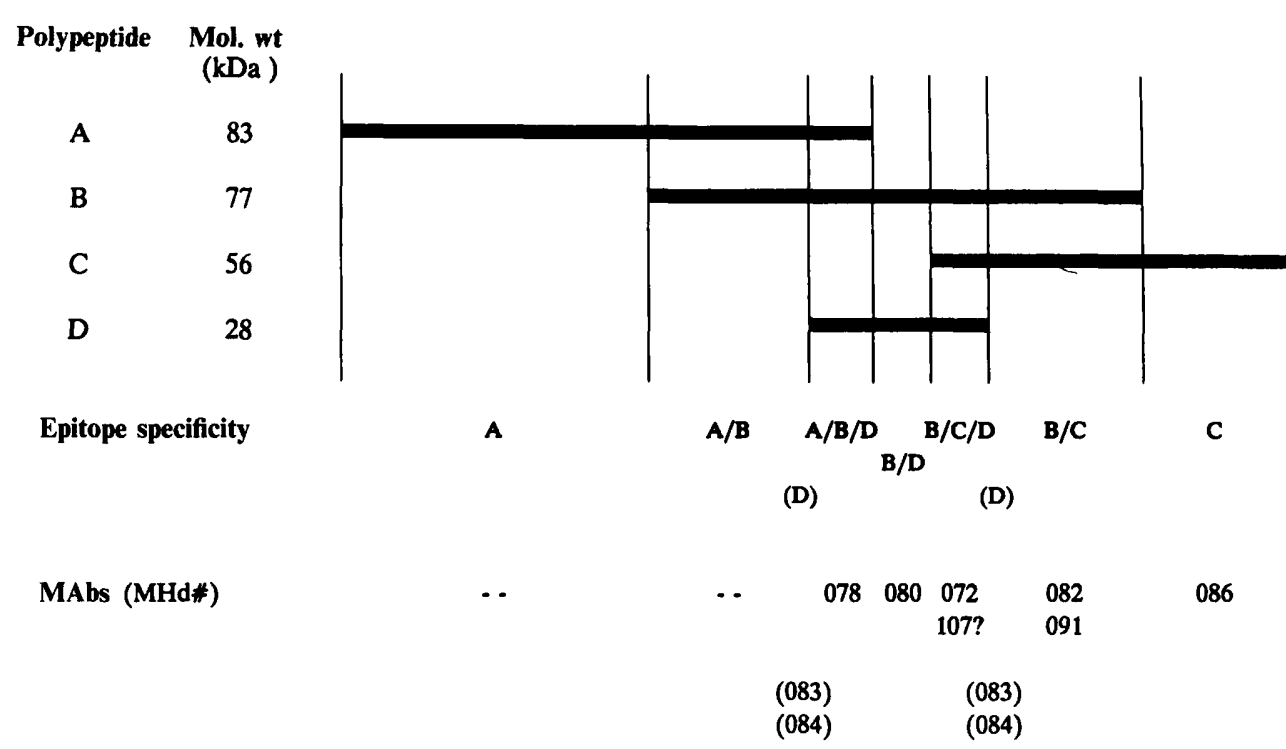

Fig. 4. A model of the sequence relationships of $H$. ducreyi-specific polypeptides as defined by the reactivities of the MAbs.

overlapping amino-acid sequences which are not shared by polypeptide C. Similarly, polypeptides B and $\mathrm{C}$ must have overlapping sequences (MHd082, MHd091) which are not shared by polypeptides A or D. The existence of an extensive but specific immune cross-reactivity suggested that these four polypeptides are members of a family of polypeptides which have overlapping sequences and that they may have been derived from the same precursor polypeptide or transcriptional unit. Based on the results reported here, we propose a sequence relationship between these four polypeptides, as shown in fig. 4 . In this model, polypeptides $\mathrm{A}$ and $\mathrm{C}$ are derived from the opposite termini of a precursor without any overlap. Polypeptide $\mathrm{D}$ is derived from the centre and overlaps partially with polypeptide A on one side and polypeptide $\mathrm{C}$ on the other side and its internal portion does not overlap with polypeptides A or C. The sequence of part of polypeptide $C$ must not overlap with other polypeptides, as indicated by the presence of a unique epitope defined by MHd086. Polypeptide $B$ is placed with its left terminus between the left termini of polypeptides $A$ and $D$, and its right terminus between the right termini of polypeptides $B$ and $D$. This placement satisfies the existence of MAbs that recognise polypeptides A, B and D (MHd078), B and D (MHd080), B, C and D (MHd072, MHd107), B and C (MHd082, MHd091), and C alone (MHd086). To account for the existence of unique epitope(s) for polypeptide D (MHd083, MHd084), which has sequence homology with other polypeptides over its entire length, we propose that each of the two MAbs may depend on the $\alpha$-amino or the carboxyl groups at either termini for recognition. Thus, all the observed epitope groups are accounted for without any inconsistencies. Based on this model, there are two other possible epitope groups, namely, a unique A epitope and a cross-reactive epitope $\mathrm{A} / \mathrm{B}$ that are not represented in our panel of MAbs. The current model is based on the premise that sequences in prokaryotic precursor polypeptides are contiguous since splicing mechanisms have not been reported. It may also be possible that these polypeptides are encoded by different genes with various degrees of homology, or have been derived from a large transcript with extensive repetitive sequences that are genetically noncontiguous or non-overlapping. Glycosylation and other post-translational modifications may also affect the reactivities with MAbs. It is possible that the variability in relative amounts of polypeptide $A$ is due to it being a pre-protein or having variable degrees of post-translational modification. The question can be further studied when antisera directed against individual purified polypeptides become available.

The ubiquitous expression of these polypeptides and their highly conserved nature suggest that they may play an essential role in the biology of $H$. ducreyi which differs from other species of Haemophilus. Although the $H$. ducreyi-specific components A, B, C and D are not OMPs, this does not preclude them from having an active role in host-parasite interactions. The soluble nature of polypeptides $\mathrm{C}$ and $\mathrm{D}$ may allow some of these to have a role as extracellular factors that are either secreted or released through lysis of the bacterium. Such soluble virulence factors have been described in several bacterial pathogens. Indeed, the current vaccines for diphtheria and tetanus are based on soluble immunogens (toxins) secreted by these pathogens. Recent studies also indicate that ribosomes from $H$. influenzae are immunogenicand protective. ${ }^{16,17}$ Thus, the location on the OM is not an absolute requirement for the induction of immunity to the pathogen. Further studies are in progress to determine the function(s) of these highly conserved $H$. ducreyispecific components. The specificity of these MAbs to $H$. ducreyi should also allow the development of sensitive immuno-diagnostics for chancroid. This has recently been recognised as an important sexually 
transmitted disease that predisposes to infection by the human immunodeficiency virus (HIV) that causes the acquired immunodeficiency syndrome (AIDS). ${ }^{18,18}$

\section{References}

1. Johnson AP, Abeck D, Davies HA. The structure, pathogenicity and genetics of Haemophilus ducreyi. $J$ Infect 1988; 17: 99-106.

2. Morse SA. Chancroid and Haemophilus ducreyi. Clin Microbiol Rev 1989; 2: 137-157.

3. Slootmans L, Vanden Berghe DA, Piot P. Typing Haemophilus ducreyi by indirect immunofluorescence assay. Genitourin Med 1985; 61: 123-126.

4. Saunders JM, Folds JD. Immunoblot analysis of antigens associated with Haemophilus ducreyi using serum from immunised rabbits. Genitourin Med 1986; 62: 321-328.

5. Museyi K, Van Dyck E, Vervoort T, Taylor D, Hoge C, Piot $P$. Use of an enzyme immunoassay to detect serum IgG antibodies to Haemophilus ducreyi. J Infect Dis 1988; 157 : 1039-1043.

6. Odumeru JA, Alfa MJ, Martin CF, Ronald AR, Jay FT. Production of monoclonal antibodies specific for Haemophilus ducreyi: a screening method to discriminate specific and cross-reacting antibodies. Hybridoma 1989; 8: 337-351.

7. Hansen EJ, Loftus TA. Monoclonal antibodies reactive with all strains of Haemophilus ducreyi. Infect Immun 1984; 44: 196-198.

8. Schalla WO, Sanders LL, Schmid GP, Tam MR, Morse SA. Use of dot-immunobinding and immunofluorescence assays to investigate clinically suspected cases of chancroid. $J$ Infect Dis 1986; 153: 879-887.

9. Laemmli UK. Cleavage of structural proteins during the assembly of the head of bacteriophage T4. Nature 1970; 227: 680-685.

10. Fraker PJ, Speck JC. Protein and cell membrane iodinations with a sparingly soluble chloroamide $1,3,4,6$-tetrachloro-
This work was supported in part by the Medical Research Council of Canada grants to F.T.J. and to A.R.R. M.J.A. is a recipient of a post-doctoral fellowship award of the Manitoba Health Research Council. The authors thank C. F. Martin for technical assistance.

3a, 6a-diphenylglycoluril. Biochem Biophys Res Commun $1978 ; 80: 849-857$.

11. Abeck D, Johnson AP, Taylor-Robinson D. Antigenic analysis of Haemophilus ducreyi by Western blotting. Epidemiol Infect 1988; 101: 151-157.

12. Abeck D, Johnson AP. Identification of surface-exposed proteins Haemophilus ducreyi. FEMS Microbiol Lett 1987; 44: 49-51.

13. Odumeru JA, Ronald AR, Albritton WL. Characterization of cell proteins of Haemophilus ducreyi by polyacrylamide gel electrophoreses. $J$ Infect Dis 1983; 148: 710-714.

14. Carlone GM, Thomas ML, Rumschlag HS, Sottnek FO. Rapid microprocedure for isolating detergent-insoluble outer membrane proteins from Haemophilus species. $J$ Clin Microbiol 1986; 24: 330-332.

15. Barenkamp SJ, Munson RS, Granoff DM. Subtyping isolates of Haemophilus influenzae type $\mathrm{b}$ by outer membrane protein profiles. $J$ Infect Dis 1981; 143: 668-676.

16. Tewari RP, Lynn M, Birnbaum AJ, Solotorovsky M. Characterization of the immunoprotective antigen of ribosomal preparations of Haemophilus influenzae. Infect Immun 1978; 19: 58-65.

17. Cabrera-Contreras R, Plescia O, Solotorovsky M, Lynn M. Enhancement of immunogenic activity of ribosomal preparations from Haemophilus influenzae by various adjuvants. Vaccine 1985; 3: 103-108.

18. Simonsen JN, Cameron DW, Gakinya MN. Human immunodeficiency virus infection among men with sexually transmitted diseases. Experience from a centre in Africa. $N$ Engl $J$ Med 1988; 319: 274-278.

19. Pepin J, Plummer FA, Brunham RC, Piot P, Cameron DW, Ronald AR. The interaction of HIV infection and other sexually transmitted diseases: an opportunity for intervention. AIDS 1989; 3: 3-9. 